\title{
PROCESSO REFLEXIVO E DESENVOLVIMENTO DO CONHECIMENTO PEDAGÓGICO DO CONTEÚDO NUMA INTERVENCฺ̃̃O FORMATIVA COM PROFESSORES DE QUÍMICA
}

\author{
Vanda Luiza dos Santos Montenegro* \\ Carmen Fernandez **
}

RESUMO: O Conhecimento Pedagógico do Conteúdo (PCK, na sigla em inglês) é reconhecido como aquele que representa o conhecimento profissional dos professores e se desenvolve na prática e por processos reflexivos. Nesta investigação analisamos o desenvolvimento do PCK de dois professores que participaram de um processo reflexivo num grupo colaborativo envolvendo ações individuais e em grupo. Os dados incluem textos escritos, vídeos de discussões orais e de aulas e o ciclo reflexivo de Smyth. A análise dos dados foi baseada no Modelo Hexagonal e nas interações discursivas. Os professores investigados, a partir do processo reflexivo, tomam consciência de algumas ações a partir da participação no grupo colaborativo, revelando um processo de desenvolvimento de PCK de modo semelhante ao proposto no modelo de raciocínio pedagógico e ação.

PALAVRAS-CHAVE: Conhecimento de professores. Conhecimento pedagógico do conteúdo. Reflexão crítica. Formação contínua. Grupo colaborativo.

\section{PROCESO REFLEXIVO Y EL DESARROLLO DEL CONOCIMIENTO PEDAGÓGICO DEL CONTENIDO EN UNA INTERVENCIÓN FORMATIVA CON PROFESSORES DE QUÍMICA}

RESUMEN: El Conocimiento Pedagógico del Contenido (PCK, la sigla en inglés) es reconocido como aquel que representa el conocimiento profesional de los profesores y se desarrolla en la práctica por procesos reflexivos. En esta investigación, analizamos el desarrollo del PCK de dos profesores que participaron de un proceso reflexivo en un grupo colaborativo envolviendo acciones individuales y en grupo. Los datos incluyen textos escritos, videos de discusiones orales y de clases y el ciclo reflexivo de Smyth. El analisis de los datos estuvo basada en el Modelo Hexagonal y en las interacciones discursivas. Los profesores investigados, a partir del proceso reflexivo, toman conciencia de algunas acciones a partir de la participación en el grupo colaborativo, revelando un proceso de desarrollo de PCK de manera semejante al propuesto en el modelo de raciocinio pedagógico y acción.

PALABRAS CLAVE: Conocimiento de profesores. Conocimiento pedagógico del contenido. Reflexión crítica. Educación continua. Grupo colaborativo.

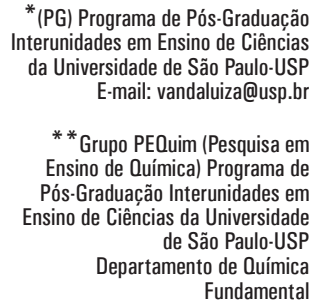

* (PG) Programa de Pós-Graduação Interunidades em Ensino de Ciências da Universidade de São Paulo-USP E-mail: vandaluiza@usp.br

* * Grupo PEQuim (Pesquisa em Ensino de Química) Programa de Pós-Graduação Interunidades em Ensino de Ciências da Universidade de São Paulo-USP Departamento de Química Fundamental 
REFLECTIVE PROCESS AND THE DEVELOPMENT OF PEDAGOGICAL CONTENT KNOWLEDGE DURING AN IN-SERVICE TRAINING INTERVENTION OF CHEMISTRY TEACHERS

ABSTRACT: The Pedagogical Content Knowledge (PCK) is recognized as the teacher professional knowledge and develops through practical activities and reflective processes. In this research, we analyze the development of PCK of two teachers who participated in a reflective process in a collaborative group involving individual and group actions. Data include written texts, videos of oral discussions and lessons and the reflective cycle of Smyth. Data analysis was based on Hexagonal Model and discursive interactions. The teachers, from the reflective process, become aware of some actions from the participation of the cooperative group, revealing a process of developing PCK similar to that proposed in the model of pedagogical reasoning and action. KEYWORDS: Teachers' knowledge. Pedagogical content knowledge. Critical reflection. In-service education. Collaborative group. 


\section{INTRODUÇÃO}

$\mathrm{Na}$ vida real é fácil reconhecer um bom professor, uma vez que todos nós já fomos estudantes e observamos o que bons professores fazem e conseguimos perceber quando um professor consegue manter a classe sob seu controle e quando conseguimos aprender em função da boa gestão de sala de aula de um professor e, ainda, quando esse não é o caso (MAMLOK-NAAMAN et al., 2013). Na base de um bom professor estão atividades diárias como organizar, controlar e avaliar o processo de aprendizagem dos estudantes, lidar com as respostas e as dificuldades dos estudantes ou fornecer informação e suporte metodológico. Assim, embora existam alguns princípios gerais para ser um bom professor de qualquer disciplina, existem várias peculiaridades relacionadas ao conteúdo específico, no nosso caso, conteúdos químicos.

\section{Conhecimento Pedagógico do Conteúdo (PCK)}

As particularidades relacionadas ao ensino de um conteúdo específico são a ideia central por trás do Conhecimento Pedagógico do Conteúdo (PCK, da expressão em inglês Pedagogical Content Knowledge). Justifica-se o uso da sigla em inglês pelo falo de ela já ser tão conhecida na literatura que é tratada como sinônimo do próprio conceito. O termo PCK foi descrito pela primeira vez por Shulman (1986) e é usado para distinguir um conhecimento profissional de professores que foca o ensino de um conteúdo específico (conteúdos de química, no nosso caso) pedagogicamente transformado. Shulman (1987) descreveu PCK como "aquele amálgama especial de conteúdo e pedagogia que é exclusivamente dos professores, sua forma especial de entendimento profissional". (SHULMAN, 1987, p.15, tradução nossa)

O PCK representa o conhecimento profissional de professores e é reconhecidamente um tipo de conhecimento adquirido na prática de professores em sala de aula (ABELL, 2007, 2008; FERNANDEZ, 2011, 2014a, 2014b; FERNANDEZ, GOES, 2014; GARRITZ, 2013; JENKINS, VEAL, 2002; KIND, 2009; LIMA, NUÑEZ, 2013; PONTE, 2012, 2013; PONTE, CHAPMAN, 2008; REALI, TANCREDI, MIZUKAMI, 2014; VAN DRIEL et al., 1998).

O construto "Conhecimento Pedagógico do Conteúdo" refere-se à interseção entre conteúdo e pedagogia e supõe:

[...] a capacidade de um professor para transformar o conhecimento do conteúdo que ele possui em formas pedagogicamente poderosas e adaptadas à diversidade dos estudantes levando em consideração as experiências e bagagens dos mesmos. (SHULMAN, 1987, tradução de FERNANDEZ, 2011, p. 2)

Para Shulman (1986) ainda, é essa capacidade de transformação do conteúdo que distingue um professor de um especialista na matéria. Shulman define o Conhecimento Pedagógico do Conteúdo como aquele: 
[...] que vai além do conhecimento da matéria em si e chega à dimensão do conhecimento da matéria para o ensino. Eu [Shulman] ainda falo de conteúdo aqui, mas de uma forma particular de conhecimento de conteúdo que engloba os aspectos do conteúdo mais próximos de seu processo de ensino. Dentro da categoria de conhecimento pedagógico do conteúdo eu [Shulman] incluo, para os tópicos mais regularmente ensinados numa determinada área do conhecimento, as formas mais úteis de representação dessas ideias, as analogias mais poderosas, ilustrações, exemplos e demonstrações - numa palavra, os modos de representar e formular o tópico que o faz compreensível aos demais. Uma vez que não há simples formas poderosas de representação, o professor precisa ter em mãos um verdadeiro arsenal de formas alternativas de representação, algumas das quais derivam da pesquisa, enquanto outras têm sua origem no saber da prática. (SHULMAN, 1986, tradução de FERNANDEZ, 2011, p. 2)

\section{Desenvolvimento do PCK}

Shulman (1987) apresenta a proposta de um Modelo de Raciocínio Pedagógico e Ação (MRPA) que representa o processo de desenvolvimento profissional de um professor, ou seja, o processo pelo qual o professor desenvolve o seu PCK (Figura 1). Shulman explica que a maior parte dos processos de ensino se inicia por alguma forma de "texto", um livro didático, um roteiro ou outro tipo de material que o professor ou os estudantes gostariam de compreender. Segundo o MRPA, dados um texto didático, objetivos educacionais e um conjunto de ideias, o raciocínio pedagógico e a ação envolvem um ciclo através de atividades de compreensão, transformação, instrução, avaliação, reflexão e nova compreensão. O ponto de partida e o término do processo são um ato de compreensão. Devido à sua natureza processual, o MRPA requer processos de raciocínio do professor sobre o conteúdo para o ensino que estão em reestruturação contínua. Sua dinâmica vai sendo enriquecida pelo contexto em que se sucede, como resultado das interações sociais que a atividade educativa implica e dos momentos distintos que caracterizam a prática docente. O MRPA é, assim, um modelo dinâmico e cíclico de reflexão e ação docente. Em cada etapa, uma série de conhecimentos e habilidades é necessária. Sendo assim, no modelo de MRPA, Shulman representa as etapas que ocorrem para o desenvolvimento da prática profissional de um professor, sempre frente a um determinado conteúdo (FERNANDEZ, 2011). 
Figura 1: Modelo de Raciocínio Pedagógico e Ação (MRPA) proposto por Shulman(1987) e adaptado por Salazar (2005). Tradução FERNANDEZ, 2011, p. 4.

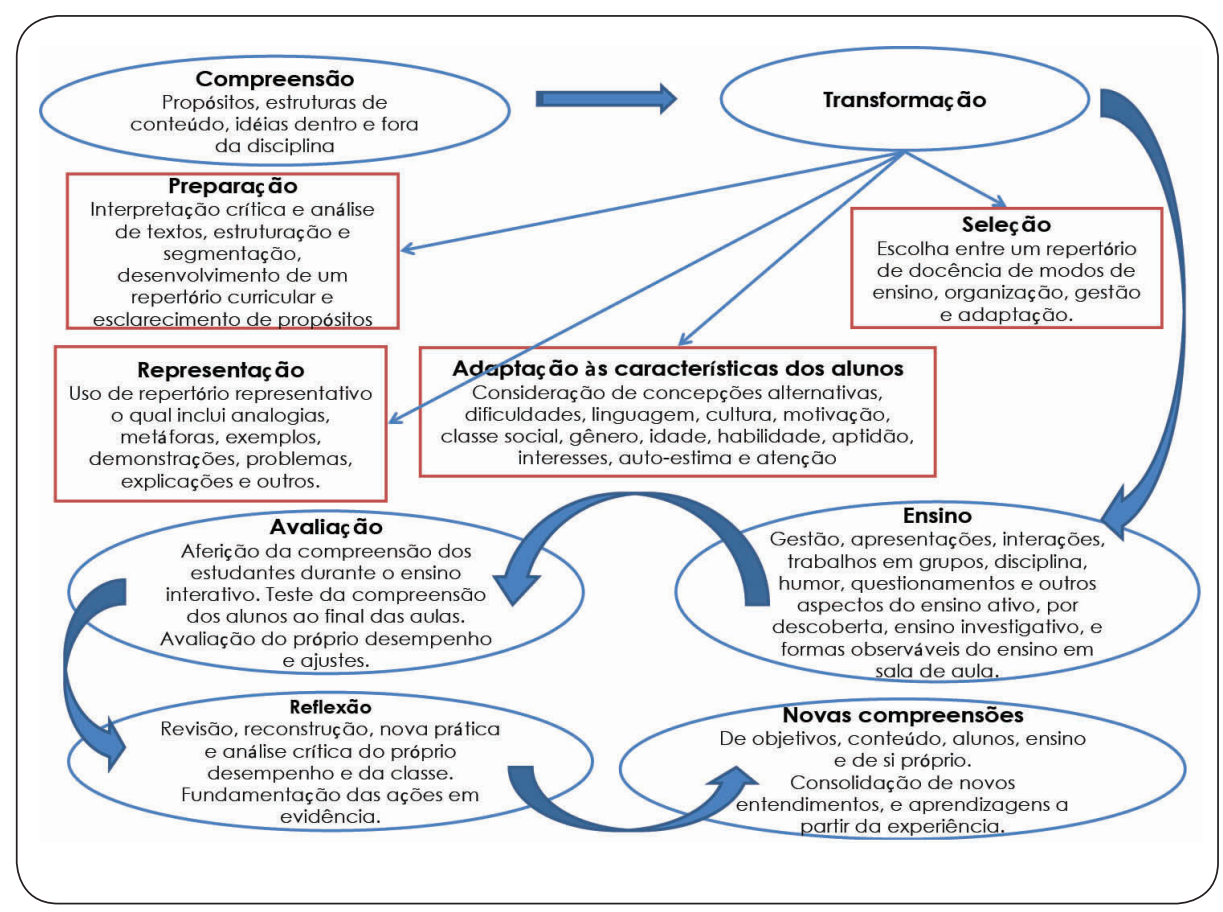

\section{Processo reflexivo}

A literatura mostra que o processo reflexivo é fundamental para o desenvolvimento do PCK (MONTENEGRO, 2011; BONARDO, FERNANDEZ, 2014; FERNANDEZ, LOPES, BONARDO, 2008; PIMENTA, 2006; SANTOS, FERNANDEZ, 2009). No Brasil e no exterior, principalmente a partir das décadas de 80 e 90, a prática reflexiva vem ganhando cada vez mais espaço na área de formação de professores, fazendo-se presente até mesmo nas reformas educacionais, como, por exemplo, nas diretrizes para a formação de professores de nosso país (BRASIL, 2001).

Perrenoud (1999), ao considerar a ideia de reflexão na ação, atribui competências profissionais necessárias às transformações da prática do professor. As competências sugeridas pelo autor são:

1. organizar e animar as situações de aprendizagem; 2. gerir o progresso das aprendizagens; 3. conceber e fazer evoluir os dispositivos de diferenciação; 4. envolver os alunos nas suas aprendizagens e no seu trabalho; 5 . trabalhar em equipe; 6. participar da gestão da escola; 7. informar e envolver os pais; 8. servir-se de novas tecnologias; 9. enfrentar os deveres e dilemas éticos da profissão; 10. gerir sua própria formação contínua. (PERRENOUD, 1999, p. 10) 
Desse modo, esse rol de competências seria necessário à atuação profissional e, portanto, ao desenvolvimento de um processo de reflexão na ação.

A ideia de que, para o desenvolvimento do seu trabalho, o professor deve atuar segundo o processo de reflexão crítica sobre sua prática emerge como uma força central e inseparável que argumenta a favor e fornece um caminho a se pensar sobre o profissional como um produtor de seus conhecimentos. É também esse processo de reflexão crítica sobre a prática que pode levar à construção do professor como um profissional autônomo. Somente ao se libertar de modelos e receitas prévias postuladas para o ensino, e através da criação de seu próprio modelo de ensino, é que o professor se liberta para atuar como profissional (FERNANDEZ, 2014b).

No Brasil, um texto importante e muito utilizado sobre as necessidades formativas dos professores de ciências foi publicado por Carvalho e Gil-Perez (2003). Os autores mostram nove necessidades formativas apontadas como as maiores dificuldades dos professores de ciências: saber dirigir o trabalho dos alunos; saber preparar atividades capazes de gerar uma aprendizagem efetiva; saber avaliar; adquirir a formação necessária para o ensino e pesquisa didática; conhecer a matéria a ser ensinada; questionar as ideias docentes de "senso comum"; adquirir conhecimentos teóricos sobre a aprendizagem das ciências; conseguir romper com visões simplistas sobre o ensino de ciências; e saber analisar criticamente o "ensino tradicional".

A proposta de Schön $(1983,1992)$ promoveu na área da pesquisa sobre formação a ideia do professor pesquisador que pode ser associada ao professor pesquisador de sua própria prática e ainda à ideia de pesquisa-ação. A pesquisa-ação fornece uma proximidade do professor com o contexto educacional permitindo conclusões mais próximas da realidade a respeito do processo de produção de conhecimento pelos professores. Há, ainda, autores que defendam a indissociabilidade entre ensino e pesquisa em virtude do seu caráter formador (DEMO, 1996; FERNANDEZ, 2014b; FREIBERGER, BERBEL, 2010; GALIAZZI, MORAES, 2002).

Para Ponte (1994, 1998), a atividade do professor requer uma combinação de conhecimentos científicos e acadêmicos na sua especialidade com conhecimentos de ordem educacional, e, portanto, é muito importante que os professores dominem perfeitamente as matérias que ensinam. Além disso, é preciso que o trabalho de formação não destrua o gosto pela disciplina, antes, o desenvolva e o ajude a amadurecer. É importante que as instituições de ensino superior, além de transmitirem conhecimento, ensinem os grandes valores das diversas disciplinas e como produzir novos conhecimentos. Nesse sentido, Pirola e Ferreira (2007) afirmam que, embora muitos professores tragam consigo esses diferentes saberes e aprendam no dia a dia com suas próprias experiências e com as experiências de seus colegas, eles não têm a oportunidade de dialogar, discutir, teorizar sobre seus problemas, o que os limita na busca de mudanças e transformações para sua prática. Sendo assim, os autores julgam 
necessário pensar a formação contínua como oportunidade para a reflexão crítica sobre a prática e de (re)construção permanente de uma identidade pessoal e profissional (FERNANDEZ, 2014b).

A formação inicial deve ser a base para o desenvolvimento profissional do professor, pois influencia não só a aquisição de conhecimentos, mas também de normas e valores (PONTE, 2000). Por outro lado, para que os professores possam desenvolver seu papel com competência, é necessário ir além da formação inicial adequada. Documentos oficiais (BRASIL, 2001; GATTI, BARRETO, ANDRÉ, 2011), apontam outros aspectos que igualmente podem contribuir para assegurar uma educação de qualidade:

A importância dos professores para a oferta de uma educação de qualidade para todos é amplamente reconhecida. A formação inicial e continuada, os planos de carreira, as condições de trabalho e a valorização desses profissionais, entre outros aspectos, ainda são desafios para as políticas educacionais no Brasil. No entanto, as condições de trabalho, a carreira e os salários que recebem nas escolas de educação básica não são atraentes nem recompensadores, e a sua formação está longe de atender às suas necessidades de atuação. Considerando o papel dos professores na qualidade da educação, é preciso não apenas garantir a formação adequada desses profissionais, mas também oferecer-lhes condições de trabalho adequadas e valorizá-los, para atrair e manter, em sala de aula, esses profissionais. (GATTI, BARRETO, ANDRÉ, 2011, p. 11)

Essa pesquisa discursa sobre uma intervenção em um processo de formação contínua. Acredita-se que, com todos os problemas emergentes da formação inicial, cabe apontar e discutir a formação ligada à ação dos professores e, em especial, relacioná-la com o processo reflexivo. O filósofo e pedagogo norte-americano John Dewey foi o precursor da ideia do pensamento reflexivo, e a frase "Nós só pensamos quando nos defrontamos com um problema" (DEWEY, 1959) aponta que, para ele, a problematização da prática é necessária para o início do processo de reflexão do professor.

Pimenta (2006) discute criticamente o conceito de "professor reflexivo" e propõe uma análise sistemática que nos permite analisar a sua gênese, e considera Schön o principal formulador do conceito:

Como professor de Estudos Urbanos no MIT (Instituto de Tecnologia de Massachusetts, EUA) até 1998, Donald Schön realizou atividades relacionadas com reformas curriculares nos cursos de formação de profissionais. Observando a prática de profissionais e valendo-se de seus estudos de filosofia, especialmente sobre John Dewey, propõe que a formação dos profissionais não mais se dê nos moldes de um currículo normativo que primeiro apresenta a ciência, depois a sua aplicação e por último um estágio que supõe a aplicação pelos alunos dos conhecimentos técnico-profissionais. O profissional assim formado, conforme a análise de Schön, não consegue dar respostas às situações que emergem no dia-a-dia profissional, porque estas ultrapassam os conhecimentos elaborados pela ciência e as respostas técnicas que esta poderia oferecer ainda não estão formuladas. (PIMENTA, 2006, p. 19) 
Schön (1983) destaca a importância da reflexão na prática docente, usa os termos reflexão na ação e reflexão sobre a ação como dois traços distintivos mais importantes do professor e propõe uma formação profissional baseada na valorização da prática profissional.

Pesquisas discutem a formação necessária do professor, muitas delas apresentam a dificuldade que professores têm em mudar efetivamente sua prática docente. Carvalho (1989) afirma que um problema encontrado em suas investigações com formação de professores diz respeito à dificuldade dos professores em realizar mudanças na "sua didática". Afirma, ainda, que o professor precisa sentir e tomar consciência desse novo contexto e do novo papel que deverá exercer na aula, sabendo que essas transformações não são tranquilas, que há resistências às mudanças.

Para Carvalho e Gil-Pérez (2006), a formação para professores deve romper com as visões simplistas sobre o ensino de ciências, e afirmam que nós professores de ciências não só carecemos de uma formação adequada como não somos conscientes de nossas insuficiências. Para avançar nesse triste cenário, seria necessário investir em uma formação com orientações construtivistas focadas na aprendizagem dos alunos, numa perspectiva de (auto)formação.

Acreditamos que a formação contínua deve ser prática, emergir de situações concretas e reais. Para Maldaner (2006), na formação contínua, os professores precisam ser auxiliados concretamente no exercício profissional. Isso inclui alocação de tempo, nova organização de horários, organização de salas ambientes, materiais de ensino, participação em congressos, assinatura de revistas e acesso a novas bibliografias e a interação com outros professores e pesquisadores em educação. Assim, a formação não será só para suprir carências, mas possibilitará aos professores buscar situações que possam proporcionar a manifestação de suas crenças e convicções, permitindo o seu desenvolvimento intelectual.

Smyth $(1986,1991)$ acredita ser necessário trabalhar criticamente com os docentes, de maneira que a capacidade de questionamento que se pretende deles possa seguir uma lógica de conscientização. $O$ trabalho proposto por ele consiste em desenvolver um processo reflexivo com os professores para que os mesmos percebam as interpretações de como se constituíram historicamente o seu contexto de atuação e as implicações da dinâmica social sobre o mesmo. Outros trabalhos já foram realizados com a perspectiva de uso do ciclo de Smyth para promoção da reflexão crítica na formação contínua (FERNANDEZ, LOPES, BONARDO, 2008; BONARDO, FERNANDEZ, 2014; SANTOS, FERNANDEZ, 2009). No quadro 1 estão apresentadas as ações do ciclo reflexivo proposto por Smyth para promover uma reflexão e emancipação por parte dos professores. Tal ciclo foi utilizado durante a disciplina ministrada, onde nossos dados foram coletados. 
Quadro 1: Ciclo reflexivo para ações de desenvolvimento profissional (SMYTH, 1991; tradução nossa).

\begin{tabular}{|c|c|c|}
\hline Ação & Questão & Descrição \\
\hline Descrever & 0 que faço? & $\begin{array}{l}\text { Está ligado à descrição da ação em forma de } \\
\text { texto para que esta fique clara aos praticantes. } \\
\text { Essa escrita pode enfocar ações rotineiras } \\
\text { ou conscientes, conversas com alunos, } \\
\text { professores, acontecimentos marcantes na } \\
\text { sala de aula, problemas específicos, dentre } \\
\text { outros. Na descrição concreta da ação torna- } \\
\text { se possível evidenciar o que está por trás de } \\
\text { cada uma. }\end{array}$ \\
\hline Informar & $\begin{array}{l}\text { Qual o significado das } \\
\text { minhas ações? }\end{array}$ & $\begin{array}{l}\text { Envolve uma busca pelos princípios que } \\
\text { embasam as ações. Está relacionada ao } \\
\text { entendimento das teorias formais que } \\
\text { sustentam as ações e aos sentidos que } \\
\text { realmente estão sendo construídos nas } \\
\text { práticas discursivas. Nessa ação há uma visita } \\
\text { ao descrever para compreender as teorias que } \\
\text { foram construídas pelo praticante ao longo da } \\
\text { sua vida e que influenciam suas ações. }\end{array}$ \\
\hline Confrontar & $\begin{array}{l}\text { Quem tem poder em } \\
\text { minha sala de aula? A } \\
\text { que interesse minha } \\
\text { prática está servindo? } \\
\text { Acredito nesses interesses } \\
\text { ou apenas os estou } \\
\text { reproduzindo? }\end{array}$ & $\begin{array}{l}\text { Está ligada ao fato de o praticante submeter } \\
\text { as teorias formais que embasam suas ações a } \\
\text { algum tipo de questionamento. No confrontar } \\
\text { as visões e ações adotadas pelos professores } \\
\text { são percebidas não como meras preferências } \\
\text { pessoais, mas como resultantes de normas } \\
\text { culturais e históricas que foram sendo } \\
\text { absorvidas. Além disso, confrontar envolve } \\
\text { buscar as inconsistências da prática entre } \\
\text { preferências pessoais e modo de agir. }\end{array}$ \\
\hline Reconstruir & $\begin{array}{c}\text { Como posso agir de forma } \\
\text { diferente? }\end{array}$ & $\begin{array}{l}\text { Relaciona-se com a proposta de emancipação } \\
\text { de si através do entendimento de que as } \\
\text { práticas acadêmicas não são imutáveis } \\
\text { e de que o poder da contestação precisa } \\
\text { ser exercido. No reconstruir, buscamos } \\
\text { alternativas para nossas açães, e voltamos a } \\
\text { ela, numa redescrição de cada ação embasada } \\
\text { e informada. }\end{array}$ \\
\hline
\end{tabular}

\section{Componentes do PCK de Park e Oliver - Modelo Hexagonal}

Para Park e Oliver (2008), os componentes do PCK incluem: a) Orientação para o ensino de ciências; b) Conhecimento do currículo de ciências; c) Conhecimento da compreensão dos alunos em ciências; d) Conhecimento da avaliação da aprendizagem em ciências; e) Conhecimento das estratégias instrucionais para o ensino de ciências; f) Eficácia do professor (Figura 2). Por ser composto de seis conhecimentos, o modelo foi chamado de Hexagonal, nele os seis componentes influenciam uns aos outros de uma maneira contínua e contextualizada. Para que o ensino efetivo possa acontecer, professores integram os componentes 
e os ordenam dentro de um dado contexto. A integração desses componentes é realizada através de reajustes a partir tanto da reflexão na ação como da reflexão sobre a ação.

A análise nesta investigação foi desenvolvida a partir desses seis componentes, pois se acredita que esse modelo permita um olhar mais holístico sobre o professor, e o vasto material coletado permite uma análise para cada componente do modelo. Um componente que chama atenção no modelo é a "Eficácia do Professor”, que permite analisar não só o conhecimento do professor, mas também suas crenças e convicções.

\section{Grupo colaborativo}

A colaboração entre professores é uma estratégia interessante para discussão de problemas reais em sala de aula, e a oportunidade de discutir a própria prática com pares que passam por situações comuns reafirma o grupo colaborativo como uma importante metodologia de trabalho para a educação. Para Boavida e Ponte (2002), a colaboração constitui uma estratégia fundamental para lidar com os problemas que se afiguram demasiadamente pesados para serem enfrentados em termos puramente individuais.

Figura 2: Modelo Hexagonal do desenvolvimento do Conhecimento Pedagógico do Conteúdo, segundo Park e Oliver (2008); tradução Fernandez (2011, p. 6).

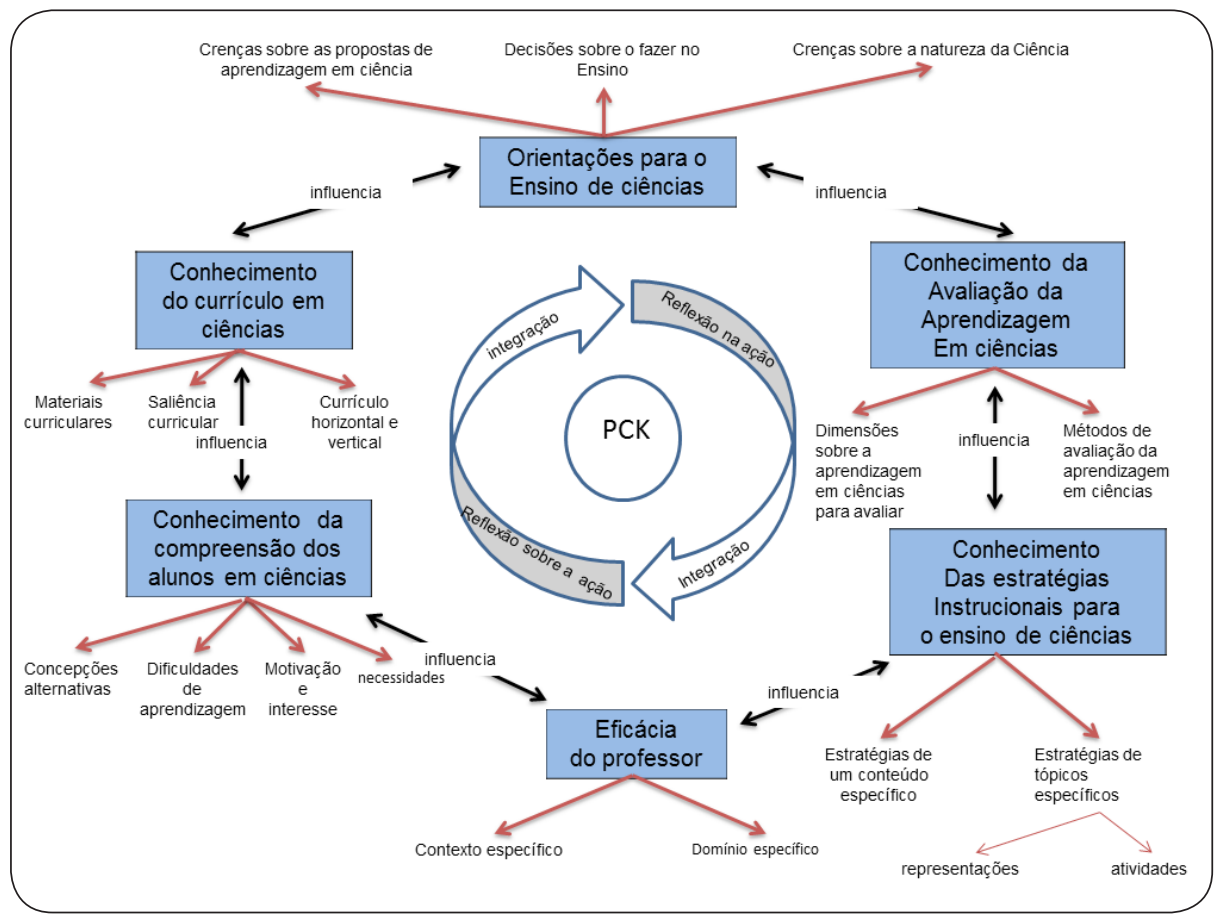


O trabalho colaborativo envolve aprendizagem relativa ao problema em questão, autoaprendizagem e aprendizagem sobre as relações humanas. Para Olson (1997):

Cada um virá com os seus próprios objetivos, propósitos, necessidades, compreensões e, através do processo de partilha, cada um partirá tendo aprendido a partir do outro. Cada um aprenderá mais acerca de si próprio, mais acerca do outro, e mais acerca do tópico em questão. (p. 25)

\section{Interações discursivas nas aulas de ciências}

Mortimer e Scott (2002), na tentativa de apresentar uma linguagem para descrever o gênero de discurso nas aulas de ciências, desenvolveram uma ferramenta que analisa a forma como os professores podem agir para guiar as interações que resultam na construção de significados em salas de aulas de ciências. A ferramenta é baseada em cinco aspectos inter-relacionados voltados para o papel do professor, que são agrupados em termos de focos de ensino, abordagem e ações, conforme apresentado no quadro 2. As interações discursivas se mostram úteis para o acesso e a documentação do PCK e já foram utilizadas em diversos trabalhos (FERNANDEZ, 2011, 2014a, 2014b; FERNANDEZ, GOES, 2014; GIROT'TO-JR, 2011; GIRO'T'TO-JR, FERNANDEZ, 2013; GOES, 2014; MONTENEGRO, 2011; OLIVEIRA JR, 2011; PEREIRA, FERNANDEZ, 2013; SALES, 2010; SILVA, 2012).

Quadro 2: A estrutura analítica: Uma ferramenta para analisar as interações e a produção de significados em salas de aula de ciências (retirado de Mortimer e Scott, 2002, p. 285)

\begin{tabular}{|c|c|c|}
\hline \multicolumn{3}{|c|}{ Aspectos da Análise } \\
\hline i. Focos de Ensino & 1. Intenções do Professor & 2. Conteúdo \\
\hline ii. Abordagem & \multicolumn{2}{|c|}{ 3. Abordagem Comunicativa } \\
\hline iii. Ações & 4. Padrões de Interação 5.1 & es do Professor \\
\hline
\end{tabular}

\section{ASPECTOS METODOLÓGICOS DA PESQUISA}

\section{Contexto da pesquisa}

Esta investigação foi desenvolvida a partir de uma intervenção formativa propiciada pelo oferecimento da disciplina de título Concepções de Ensino e Aprendizagem na teoria e na prática de professores de Química, pelo Programa de Pós-Graduação Interunidades em Ensino de Ciências da Universidade de São Paulo, ministrada no primeiro semestre de 2007 pela última autora deste artigo. A intervenção formativa foi pautada nas seguintes etapas: i.) leitura de textos e discussões sobre as distintas concepções de ensino-aprendizagem e compilação das 
características de cada concepção; ii.) os professores pós-graduandos assistiram a vídeos de aulas que possuíam algumas características das abordagens estudadas e as aulas foram analisadas a partir da produção do ciclo reflexivo de Smyth, descrever, informar, confrontar e reconstruir; iii.) os professores foram convidados a gravar uma aula em seu contexto real de escola e alunos; iv.) produção do ciclo reflexivo de Smyth a partir da própria aula e da aula de um par (os professores foram agrupados em pares para assistirem e analisarem as aulas um do outro); v.) exibição do vídeo de aula de cada professor e discussão da aula pelo grupo colaborativo, vi.) nova produção do ciclo reflexivo de Smyth após a discussão do grupo colaborativo.

\section{Sujeitos da pesquisa}

Doze professores participaram da intervenção formativa apresentada no contexto da pesquisa, todos realizaram a regência de aula e participaram do processo reflexivo. Entretanto, a proposta era gravar uma segunda aula com o mesmo conteúdo em 2009 e isso limitou expressivamente a participação dos professores, uma vez que nem todos ministraram o mesmo conteúdo nesse ano. Assim, a amostra contou com dois professores em análises diretas.

Esses dois professores lecionavam em instituições privadas, ambos eram alunos regulares no curso de pós-graduação em ensino de ciências, área de concentração química. P1 é do sexo masculino, engenheiro químico, licenciado em química, especialista em ensino de química e sua experiência docente era de três anos no momento da pesquisa. P2 é do sexo feminino, bacharel em tecnologia, licenciada em química e sua experiência docente era de seis anos no momento da pesquisa.

\section{Coleta de dados}

$\mathrm{Na}$ análise do desenvolvimento do Conhecimento Pedagógico do Conteúdo dos dois sujeitos de nossa investigação, analisamos os materiais escritos desenvolvidos na disciplina; registros em áudio e vídeo de duas aulas de cada professor, sendo uma antes e outra depois da intervenção formativa; registro audiovisual da discussão sobre a análise das primeiras aulas gravadas durante a intervenção formativa; o ciclo reflexivo de Smyth antes e depois da intervenção formativa e uma entrevista semiestruturada sobre avaliação que foi realizada por Tacoshi (2008).

\section{Análise dos dados}

Os dois professores ministraram aulas de conteúdos químicos distintos, P1 ensinando indicadores ácido e base e P2 ensinando soluções, ambos no primeiro ano do Ensino Médio, porém em escolas diferentes. A análise dos materiais foi feita por análise de conteúdo utilizando as categorias do Modelo Hexagonal de Park e Oliver (2008) apresentado na figura 2. 
Os materiais produzidos pelos professores durante a disciplina foram extensivamente lidos sob o enfoque dos componentes do modelo hexagonal. As gravações das aulas, das entrevistas e das discussões sobre as reflexões da aula durante a intervenção formativa foram lidas diversas vezes em busca de elementos que pudessem ser caracterizados com os componentes do modelo. Para cada um dos componentes do modelo, foram analisados os seguintes materiais: atividades produzidas durante a intervenção, vídeo das aulas gravadas em contexto real dos professores; discussão da aula de cada professor pelo grupo colaborativo, ciclo reflexivo de Smyth e, por fim, a entrevista sobre avaliação (TACOSHI, 2008).

No intuito de analisar as interações ocorridas nas aulas gravadas (antes e após a intervenção formativa) utilizou-se a ferramenta de Mortimer e Scott (2002) que permitiu analisar a forma como os professores agiram para guiar suas interações que resultaram na construção de significados em suas aulas.

\section{RESULTADOS}

Apresenta-se a seguir, nos quadros 3 e 4, um resumo dos principais resultados encontrados para cada um dos componentes do modelo hexagonal do desenvolvimento do PCK dos professores P1 e P2, respectivamente.

Quadro 3: Resumo dos principais resultados encontrados nos componentes do Modelo Hexagonal - P1.

\begin{tabular}{|c|c|c|}
\hline \multicolumn{3}{|c|}{ Principais resultados para cada componente } \\
\hline $\begin{array}{c}\text { Componentes do } \\
\text { PCK }\end{array}$ & $\begin{array}{l}\text { Descrição do } \\
\text { componente }\end{array}$ & Aspectos observáveis \\
\hline $\begin{array}{c}\text { Orientações } \\
\text { para o ensino de } \\
\text { ciências } \\
\text { Processo; rigor } \\
\text { acadêmico; } \\
\text { didática; mudança } \\
\text { conceitual; } \\
\text { atividade dirigida; } \\
\text { descoberta; } \\
\text { ciência baseada } \\
\text { em projetos; } \\
\text { investigação e; } \\
\text { investigação } \\
\text { dirigida }\end{array}$ & $\begin{array}{l}\text { Refere-se a } \\
\text { crenças do } \\
\text { professor sobre } \\
\text { as propostas } \\
\text { e objetivos } \\
\text { para ensinar } \\
\text { ciências, serve } \\
\text { como um mapa } \\
\text { conceitual que } \\
\text { guia as decisões } \\
\text { instrucionais, o } \\
\text { uso dos materiais } \\
\text { curriculares, } \\
\text { as estratégias } \\
\text { instrucionais e } \\
\text { a avaliação de } \\
\text { aprendizagem dos } \\
\text { alunos. }\end{array}$ & 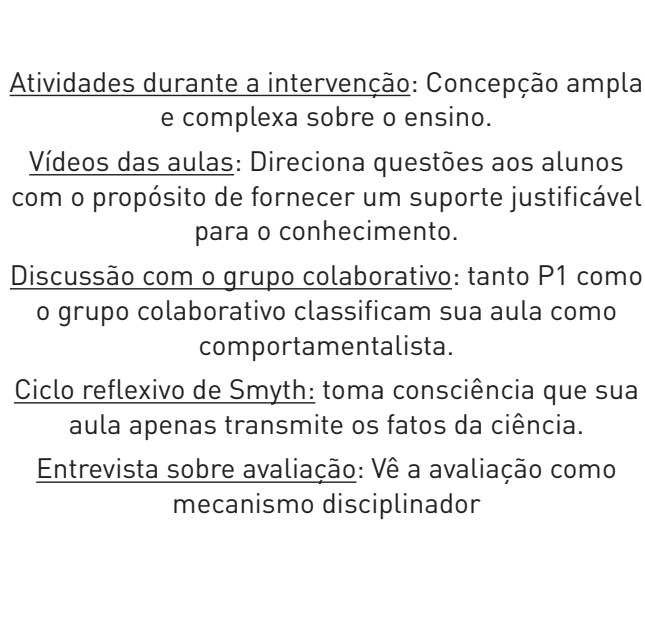 \\
\hline
\end{tabular}




\begin{tabular}{|c|c|c|}
\hline $\begin{array}{l}\text { Conhecimento } \\
\text { do currículo em } \\
\text { ciências }\end{array}$ & $\begin{array}{l}\text { Refere-se ao } \\
\text { conhecimento } \\
\text { dos professores } \\
\text { nos materiais } \\
\text { curriculares, } \\
\text { indica o } \\
\text { entendimento do } \\
\text { professor sobre } \\
\text { a importância do } \\
\text { tópico em relação } \\
\text { ao currículo como } \\
\text { um todo. }\end{array}$ & $\begin{array}{l}\text { Atividades durante a intervenção: dá indícios de que } \\
\text { o professor conhece o currículo de ciências. } \\
\frac{\text { Vídeos das aulas: } \mathrm{P} 1 \text { teve dificuldade em tornar-se }}{\text { claro aos alunos em grande parte da aula. }} \\
\frac{\text { Discussão com o grupo colaborativo: considera que }}{\text { o professor fez escolhas conscientes nos materiais }} \\
\text { didáticos, mas sentiu dificuldade em manter o } \\
\text { propósito proposto pelo material utilizado. } \\
\frac{\text { Ciclo reflexivo de Smyth: Toma consciência que sua }}{\text { aula foi mal planejada. }} \\
\frac{\text { Entrevista sobre avaliação: questiona a qualidade da }}{\text { sua formação como professor }}\end{array}$ \\
\hline $\begin{array}{c}\text { Conhecimento } \\
\text { da avaliação da } \\
\text { aprendizagem em } \\
\text { ciências }\end{array}$ & $\begin{array}{l}\text { Refere-se às } \\
\text { dimensões da } \\
\text { aprendizagem } \\
\text { em ciências que } \\
\text { são importantes } \\
\text { avaliar, inclui o } \\
\text { conhecimento } \\
\text { dos métodos } \\
\text { pelos quais a } \\
\text { aprendizagem } \\
\text { pode ser avaliada. }\end{array}$ & 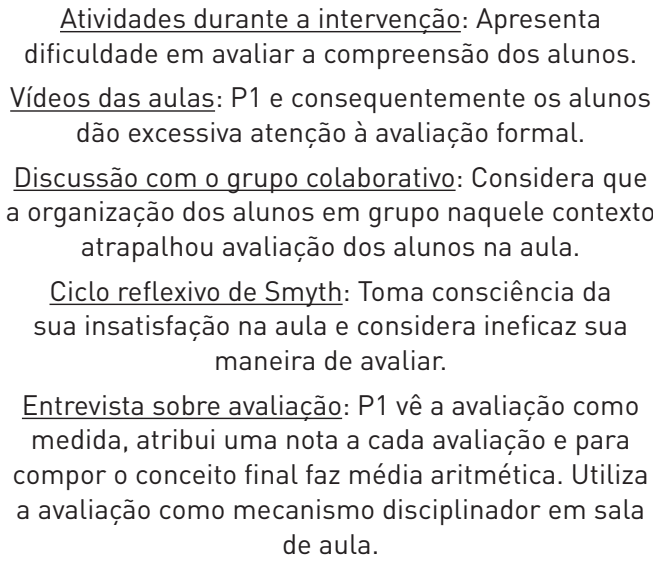 \\
\hline $\begin{array}{l}\text { Conhecimento } \\
\text { da compreensão } \\
\text { dos alunos em } \\
\text { ciências }\end{array}$ & $\begin{array}{l}\text { Refere-se ao } \\
\text { conhecimento } \\
\text { que o professor } \\
\text { deve ter sobre } \\
\text { a compreensão } \\
\text { dos alunos no } \\
\text { tópico trabalhado, } \\
\text { incluindo a } \\
\text { identificação } \\
\text { das dificuldades } \\
\text { dos alunos, o } \\
\text { aparecimento } \\
\text { de concepções } \\
\text { alternativas, a } \\
\text { motivação, o } \\
\text { interesse e as } \\
\text { necessidades } \\
\text { deles. }\end{array}$ & $\begin{array}{l}\text { Atividades durante a intervenção: tem dificuldade } \\
\text { em reconhecer se o aluno compreendeu o conteúdo } \\
\text { trabalhado. } \\
\text { Vídeos das aulas: utiliza nas aulas a abordagem } \\
\text { interativa de autoridade, os padrões predominantes } \\
\text { da interação são: I-R-A - P1 faz a pergunta } \\
\text { (I-iniciação do professor), os alunos respondem } \\
\text { (R-resposta do aluno) e o professor avalia } \\
\text { (A-avaliação do professor), a tríade é repetida. } \\
\text { Discussão com o grupo colaborativo: os alunos têm } \\
\text { dificuldade em compreender a aula. } \\
\text { Ciclo reflexivo de Smyth: O professor toma } \\
\text { consciência das dificuldades dos alunos. } \\
\text { Entrevista sobre avaliação: há divergência entre o } \\
\text { ensino real e o idealizado pelo professor. }\end{array}$ \\
\hline
\end{tabular}




\begin{tabular}{|c|c|c|}
\hline $\begin{array}{c}\text { Conhecimento } \\
\text { das estratégias } \\
\text { instrucionais } \\
\text { para o ensino de } \\
\text { ciências }\end{array}$ & $\begin{array}{c}\text { Refere-se às } \\
\text { estratégias } \\
\text { instrucionais } \\
\text { utilizadas pelo } \\
\text { professor em } \\
\text { suas aulas, são } \\
\text { abordagens } \\
\text { gerais, que são } \\
\text { condizentes com } \\
\text { os objetivos para o } \\
\text { ensino de ciências } \\
\text { ou específicas, } \\
\text { aplicadas para o } \\
\text { ensino de tópicos } \\
\text { particulares } \\
\text { dentro do domínio } \\
\text { da ciência }\end{array}$ & $\begin{array}{l}\frac{\text { Atividades durante a intervencão: tem dificuldade }}{\text { em utilizar estratégias eficazes. }} \\
\text { Vídeos das aulas: Confusões na aula não permitem } \\
\text { que o aluno avance em seus conhecimentos. } \\
\text { Discussão com o grupo colaborativo: O professor faz } \\
\text { uso de estratégias eficazes, mas não consegue dar } \\
\text { uma aula eficaz. } \\
\frac{\text { Ciclo reflexivo de Smyth: Toma consciência das }}{\text { estratégias que poderia ter utilizado. }} \\
\frac{\text { Entrevista sobre avaliação: Há contradição entre o }}{\text { real e o ideal. }}\end{array}$ \\
\hline $\begin{array}{l}\text { Eficácia do } \\
\text { professor }\end{array}$ & $\begin{array}{c}\text { Está mais } \\
\text { relacionado com } \\
\text { a afetividade } \\
\text { do que com o } \\
\text { conhecimento, é a } \\
\text { percepção que os } \\
\text { professores têm } \\
\text { deles mesmos. } \\
\text { O aumento } \\
\text { da eficácia } \\
\text { do professor } \\
\text { o encoraja a } \\
\text { estabelecer } \\
\text { objetivos mais } \\
\text { audaciosos que } \\
\text { se manifestam } \\
\text { num interesse } \\
\text { em testar novas } \\
\text { estratégias de } \\
\text { ensino. }\end{array}$ & $\begin{array}{l}\text { Atividades durante a intervenção: Apresenta } \\
\text { componentes importantes sobre a concepção do que } \\
\text { é ser um bom professor. } \\
\text { Vídeos das aulas: não demonstra satisfação com a } \\
\text { aula, recorre para autoridade em partes dela. } \\
\text { Discussão com o grupo colaborativo: Demonstra em } \\
\text { alguns momentos insatisfação com a própria aula. } \\
\text { Ciclo reflexivo de Smyth: Toma consciência das suas } \\
\text { possíveis facilidades e dificuldades na profissão. } \\
\text { Entrevista sobre avaliação: Orgulha-se de ser } \\
\text { professor, é respeitado na escola, mas não } \\
\text { demonstra satisfação com a profissão. }\end{array}$ \\
\hline
\end{tabular}

Quadro 4: Resumo dos principais resultados encontrados nos componentes do Modelo Hexagonal - P2.

\begin{tabular}{|c|c|c|}
\hline \multicolumn{3}{|c|}{ Principais resultados para cada componente } \\
\hline $\begin{array}{c}\text { Componentes do } \\
\text { PCK }\end{array}$ & $\begin{array}{l}\text { Descrição do } \\
\text { componente }\end{array}$ & Aspectos observáveis \\
\hline $\begin{array}{c}\text { Orientações } \\
\text { para o ensino de } \\
\text { ciências } \\
\text { Processo; rigor } \\
\text { acadêmico; } \\
\text { didática; mudança } \\
\text { conceitual; } \\
\text { atividade dirigida; } \\
\text { descoberta; } \\
\text { ciência baseada } \\
\text { em projetos; } \\
\text { investigação; } \\
\text { e investigação } \\
\text { dirigida. }\end{array}$ & $\begin{array}{c}\text { Refere-se a } \\
\text { crenças do } \\
\text { professor sobre } \\
\text { propostas } \\
\text { e objetivos } \\
\text { para ensinar } \\
\text { ciências, serve } \\
\text { como um mapa } \\
\text { conceitual que } \\
\text { guia as decisões } \\
\text { instrucionais, o } \\
\text { uso dos materiais } \\
\text { curriculares, } \\
\text { as estratégias } \\
\text { instrucionais e } \\
\text { a avaliação de } \\
\text { aprendizagem dos } \\
\text { alunos. }\end{array}$ & $\begin{array}{l}\text { Atividades durante a intervenção: Vê o ensino como } \\
\text { uma troca, o professor aprende quando ensina e o } \\
\text { aluno ensina enquanto aprende. } \\
\text { Vídeos das aulas: As aulas são expositivas com o uso } \\
\text { de experimentação de maneira demonstrativa. } \\
\text { Discussão com o grupo colaborativo: A aula de P2 } \\
\text { tem o formato que é exigido pela instituição onde } \\
\text { trabalha, ensino propedêutico. } \\
\text { Ciclo reflexivo de Smyth: Expõe que traz o conteúdo } \\
\text { pronto e o aluno limita-se passivamente a escutar. } \\
\text { Entrevista sobre avaliação: Vê o aprendizado dos } \\
\text { alunos como treinamento e considera importante } \\
\text { que os alunos resolvam exercícios e pratiquem } \\
\text { bastante. }\end{array}$ \\
\hline
\end{tabular}




\begin{tabular}{|c|c|c|}
\hline $\begin{array}{l}\text { Conhecimento } \\
\text { do currículo em } \\
\text { ciências }\end{array}$ & $\begin{array}{l}\text { Refere-se ao } \\
\text { conhecimento } \\
\text { dos professores } \\
\text { nos materiais } \\
\text { curriculares, } \\
\text { indica o } \\
\text { entendimento do } \\
\text { professor sobre } \\
\text { a importância do } \\
\text { tópico em relação } \\
\text { ao currículo como } \\
\text { um todo. }\end{array}$ & $\begin{array}{l}\text { Atividades durante a intervenção: Apresenta um } \\
\text { eficiente conhecimento de currículo nas atividades } \\
\text { de discussão ocorridas durante a intervenção. } \\
\text { Vídeos das aulas: Dá indícios de que conhece bem o } \\
\text { conteúdo que está ensinando. } \\
\text { Discussão com o grupo colaborativo: Desenvolve } \\
\text { aulas tradicionais devido à imposição do sistema } \\
\text { apostilado. Não tem liberdade de planejar e executar } \\
\text { suas aulas. } \\
\text { Ciclo reflexivo de Smyth: Afirma atender à } \\
\text { concepção comportamentalista em suas aulas, } \\
\text { confronta a abordagem e em seguida reconstrói sua } \\
\text { aula. } \\
\text { Entrevista sobre avaliação: Expõe exemplos } \\
\text { coerentes de conteúdos, dando indícios do seu } \\
\text { conhecimento de currículo. }\end{array}$ \\
\hline $\begin{array}{c}\text { Conhecimento } \\
\text { da avaliação da } \\
\text { aprendizagem em } \\
\text { ciências }\end{array}$ & $\begin{array}{l}\text { Refere-se às } \\
\text { dimensões da } \\
\text { aprendizagem } \\
\text { em ciências que } \\
\text { são importantes } \\
\text { avaliar, inclui o } \\
\text { conhecimento } \\
\text { dos métodos } \\
\text { pelos quais a } \\
\text { aprendizagem } \\
\text { pode ser avaliada. }\end{array}$ & $\begin{array}{l}\text { Atividades durante a intervenção: A avaliação } \\
\text { dos conhecimentos dos alunos deve ir além dos } \\
\text { conteúdos trabalhados. } \\
\text { Vídeos das aulas: P2 avalia a aprendizagem dos } \\
\text { alunos pela participação deles na resolução coletiva } \\
\text { de exercícios. } \\
\text { Discussão com o grupo colaborativo: P2 não elabora } \\
\text { nem aplica a avaliação formal do final do semestre. } \\
\text { Ciclo reflexivo de Smyth: Reflete que os alunos são } \\
\text { ouvintes em suas aulas. } \\
\text { Entrevista sobre avaliação: Os alunos devem } \\
\text { aprender, mas não deve ser desconsiderado o } \\
\text { objetivo deste conhecimento, passar no vestibular. } \\
\text { Não está satisfeita com a metodologia de avaliação } \\
\text { da escola. }\end{array}$ \\
\hline $\begin{array}{l}\text { Conhecimento } \\
\text { da compreensão } \\
\text { dos alunos em } \\
\text { ciências }\end{array}$ & $\begin{array}{l}\text { Refere-se ao } \\
\text { conhecimento } \\
\text { que o professor } \\
\text { deve ter sobre } \\
\text { a compreensão } \\
\text { dos alunos no } \\
\text { tópico trabalhado, } \\
\text { incluindo a } \\
\text { identificação } \\
\text { das dificuldades } \\
\text { dos alunos, o } \\
\text { aparecimento } \\
\text { de concepções } \\
\text { alternativas, a } \\
\text { motivação, o } \\
\text { interesse e as } \\
\text { necessidades } \\
\text { deles. }\end{array}$ & $\begin{array}{c}\text { Atividades durante a intervenção: A aprendizagem } \\
\text { significativa acontece quando os alunos são capazes } \\
\text { de aplicar o conhecimento em diferentes situações. } \\
\text { Vídeos das aulas: utiliza nas aulas a abordagem } \\
\text { interativa de autoridade, o padrão predominante } \\
\text { da interação é do tipo I-R-A, P2 faz a pergunta } \\
\text { (I-iniciação do professor), os alunos respondem } \\
\text { (R-resposta do aluno) e o professor avalia } \\
\text { (A-avaliação do professor), a tríade é repetida. } \\
\text { Discussão com o grupo colaborativo: Tem a } \\
\text { necessidade de cumprir um currículo extenso em } \\
\text { um curto espaço de tempo. } \\
\text { Ciclo reflexivo de Smyth: Preocupa-se com a } \\
\text { compreensão dos alunos, acredita que ela não } \\
\text { ocorre eficazmente no formato de aula que pratica. } \\
\text { No reconstruir propõe ações que facilitaram a } \\
\text { compreensão dos alunos. } \\
\text { Entrevista sobre avaliação: Uma maneira eficaz } \\
\text { de avaliar a compreensão dos alunos é atentar ao } \\
\text { retorno que eles dão ao que é ensinado. }\end{array}$ \\
\hline
\end{tabular}




\begin{tabular}{|c|c|c|}
\hline $\begin{array}{c}\text { Conhecimento } \\
\text { das estratégias } \\
\text { instrucionais } \\
\text { para o ensino de } \\
\text { ciências }\end{array}$ & $\begin{array}{l}\text { Refere-se às } \\
\text { estratégias } \\
\text { instrucionais } \\
\text { utilizadas pelo } \\
\text { professor em } \\
\text { suas aulas, são } \\
\text { abordagens } \\
\text { gerais, que são } \\
\text { condizentes com } \\
\text { os objetivos para o } \\
\text { ensino de ciências } \\
\text { ou específicas, } \\
\text { aplicadas para o } \\
\text { ensino de tópicos } \\
\text { particulares } \\
\text { dentro do domínio } \\
\text { da ciência. }\end{array}$ & $\begin{array}{l}\text { Atividades durante a intervenção: Desenvolve } \\
\text { aulas expositivas, mas acredita em estratégias que } \\
\text { facilitam a interação. } \\
\text { Vídeos das aulas: Para explicar diluição prepara um } \\
\text { suco de pêssego e paralelamente explica o conceito } \\
\text { e constrói na lousa sentenças matemáticas para } \\
\text { cálculo de concentração. } \\
\text { Discussão com o grupo colaborativo: os alunos } \\
\text { estavam enfileirados e as interações eram } \\
\text { professor-aluno de maneira individual. As } \\
\text { informações eram levadas de forma tradicional. } \\
\text { Ciclo reflexivo de Smyth: P2 critica suas estratégias, } \\
\text { reconstrói sua aula, porém deixa claro que a aula } \\
\text { reconstruída só seria possível em outra instituição. } \\
\text { Entrevista sobre avaliação: Trabalha em uma } \\
\text { instituição de ensino regular que também é voltada } \\
\text { para o ensino propedêutico. }\end{array}$ \\
\hline $\begin{array}{c}\text { Eficácia do } \\
\text { professor }\end{array}$ & $\begin{array}{c}\text { Está mais } \\
\text { relacionado com } \\
\text { a afetividade } \\
\text { do que com o } \\
\text { conhecimento, é a } \\
\text { percepção que os } \\
\text { professores têm } \\
\text { deles mesmos. } \\
\text { O aumento } \\
\text { da eficácia } \\
\text { do professor } \\
\text { o encoraja a } \\
\text { estabelecer } \\
\text { objetivos mais } \\
\text { audaciosos que } \\
\text { se manifestam } \\
\text { num interesse } \\
\text { em testar novas } \\
\text { estratégias de } \\
\text { ensino. }\end{array}$ & $\begin{array}{l}\text { Atividades durante a intervenção: o bom professor é } \\
\text { aquele que conhece seu aluno e sabe o conteúdo, a } \\
\text { forma e o ritmo com que deve trabalhar. } \\
\text { Vídeos das aulas: As aulas mostram uma professora } \\
\text { muito segura no que faz, brinca durante as aulas, } \\
\text { tem a participação a simpatia dos alunos. } \\
\text { Discussão com o grupo colaborativo: O grupo } \\
\text { considera que sua aula funciona, considera a } \\
\text { professora dinâmica, engraçada e descontraída. } \\
\text { Ciclo reflexivo de Smyth: Tem plena convicção da } \\
\text { abordagem utilizada em suas aulas, não economiza } \\
\text { críticas à aula, no entanto, considera que está de } \\
\text { acordo com a instituição em que trabalha. } \\
\text { Entrevista sobre avaliação: faz relato de uma } \\
\text { experiência que teve em outra instituição e mostra } \\
\text { que pode ser diferente em um contexto diferente. }\end{array}$ \\
\hline
\end{tabular}

Os dados coletados foram relacionados às categorias do modelo Hexagonal. $\mathrm{Na}$ figura 3 apresenta-se o modelo conforme os dados analisados do professor P1. Vale ressaltar que a posição dos componentes corresponde ao apresentado no modelo hexagonal original.

P1 tem o componente 5 - Conhecimento das estratégias instrucionais levemente mais ampliado que os demais componentes, porém o seu PCK é incipiente, pois, embora ele conhecesse as estratégias importantes para o ensino, em seu contexto, elas não foram parceiras na construção do conhecimento pelos alunos. O trabalho em grupo, que normalmente facilita a interação entre os alunos, entre os alunos e o professor e entre os alunos e o conhecimento, na aula de P1, foi responsável pela indisciplina. Faltou no professor a integração dos demais componentes para que sua aula fosse eficaz. Após a discussão com o grupo colaborativo, o professor melhorou esse componente, entretanto, apoiados nos autores do modelo, acredita-se que a melhora de um único componente pode não ser suficiente para o avanço do PCK. 
Figura 3: Modelo hexagonal para P1.

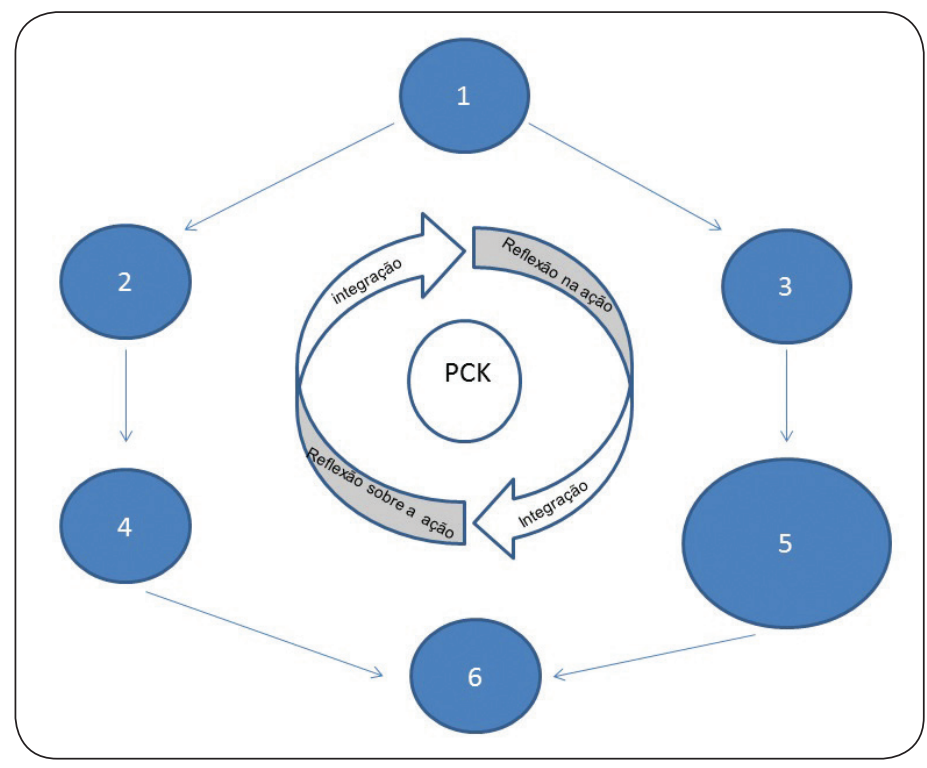

$\mathrm{Na}$ figura 4 apresenta-se o modelo conforme os dados analisados do professor P2.

Figura 4: Modelo hexagonal para P2.

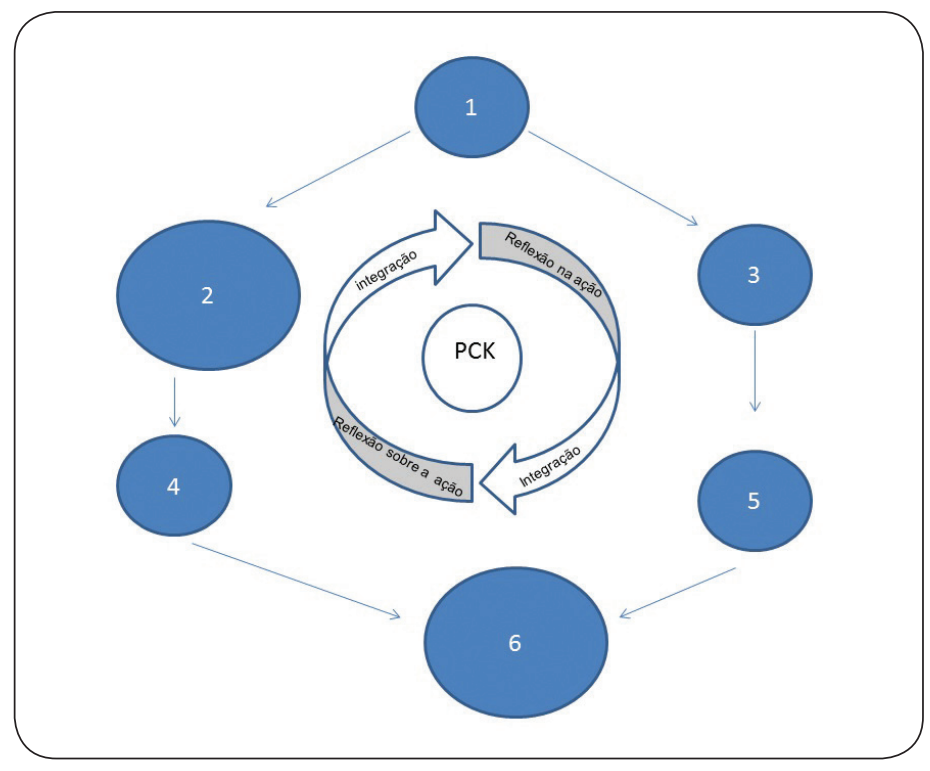


Acredita-se que P2 tem os componentes 2-Conhecimento do currículo em ciências e 6-Eficácia de professor - mais desenvolvidos e acredita-se que a impossibilidade de desenvolver as aulas como acredita, dá-se devido à imposição da instituição onde trabalha, o que pode ter influenciado na análise dos outros componentes. Analisou-se que P2 teve o seu PCK sensivelmente desenvolvido.

Considerando o Modelo de Raciocínio Pedagógico e Ação (MRPA, figura 1), P1 sente dificuldade para desenvolver seu PCK já na atividade "Compreensão", pois apresenta problemas com o conteúdo específico. Acredita-se, com base no modelo, que, quando o professor tem dificuldade de "Compreensão", não "Transforma”, apenas reproduz, e isso compromete significativamente o ciclo.

Por outro lado, P2 compreende o conteúdo na aula analisada, passa para a atividade "Transformação", faz a seleção do conteúdo, realiza adaptações, representa e prepara o conteúdo, mas sempre tendo em vista um ensino propedêutico. Assim, quando passa para a atividade "Ensino", protagoniza as ações didáticas de acordo com as exigências da instituição em que trabalha, da mesma maneira acontece na atividade "Avaliação". A professora P2 afirma refletir sobre o ensino, porém diz não conseguir elaborar uma nova compreensão naquele contexto profissional.

Assim, as orientações para o ensino de ciências, diferentes para os dois professores investigados, influenciam sobremaneira o que se observa em suas ações didáticas em sala de aula. Essas orientações são modeladas pelo contexto e recebem estímulos positivos e negativos das ações eficazes de cada um. O professor P1 não está contente com seu ensino pouco eficaz e faz tentativas de mudança, embora frustradas. Sua percepção de seu ensino era equivocada e ele percebe, com ajuda do grupo colaborativo e com sua própria reflexão, que o que faz não se aproxima do que deseja. Tanto a reflexão como a baixa eficácia impulsionam esse professor para uma mudança. A professora P2 está envolvida num contexto que aprisiona sua prática e a impede de mudar. Além disso, essa professora se mostra muito eficaz nesse contexto e, assim, embora veja motivos para mudança após a reflexão, sua eficácia e o contexto em que trabalha a mantêm num modelo didático no qual não acredita.

\section{CONCLUSÕES}

Analisaram-se dois professores de química do Ensino Médio durante um processo de formação contínua, no contexto de uma disciplina de pós-graduação. Foram analisados os materiais que eles produziram durante a disciplina, os vídeos de aula gravados em contexto real, a discussão do grupo colaborativo sobre a aula de cada professor, o ciclo reflexivo de Smyth, que foi desenvolvido sobre suas aulas, e uma entrevista sobre avaliação.

O uso da gravação do vídeo da aula e sua reflexão no grupo colaborativo, além do ciclo de Smith, utilizados na disciplina Concepções de Ensino e Aprendizagem 
na Teoria e na Prática de Professores de Química, revelaram-se como poderosas ferramentas para reflexão da própria prática e para o desenvolvimento do PCK. O ciclo reflexivo de Smyth, desenvolvido durante a disciplina que serviu de intervenção para a coleta dos dados, promoveu a reflexão da própria aula e da ação educativa dos professores com consequente desenvolvimento de elementos do PCK para todos os professores envolvidos no grupo.

A análise das interações discursivas nas aulas dos professores é reveladora das orientações para o ensino de ciências que embasam esses professores.

P1 apresenta uma prática contraditória que foi revelada pelo padrão de interação de suas aulas, pela sua concepção de avaliação, pelo material curricular selecionado, pelo planejamento de sua aula e pela aula propriamente dita.

O desenvolvimento dos ciclos reflexivos de Smyth para as próprias aulas, antes e após a intervenção do grupo colaborativo, aponta que P1, a partir da escrita das quatro ações e com a discussão no grupo, toma consciência de algumas características de sua aula que não lhe eram transparentes, não demonstra satisfação com sua atuação docente na aula e questiona sua eficácia como professor. As ferramentas utilizadas durante o processo reflexivo individual ganham um aprofundamento ao serem apresentadas ao grupo. É na discussão no grupo, e após uma análise detalhada individual, que novas compreensões são realizadas tanto pelo professor investigado como por todos os professores que compõem o grupo colaborativo. Assim, a baixa eficácia percebida pelo professor durante a ação formativa mobiliza esse professor para o desenvolvimento de seu PCK.

P2 acredita que sua aula apresenta características da concepção comportamentalista de ensino, e tal crença foi reafirmada pela discussão do grupo colaborativo. Embora P2 tenha plena convicção dos complicadores para a aprendizagem do aluno utilizando essa abordagem, considera que seja necessária para seu contexto, acreditando-se eficaz ensinando aquele conteúdo para aqueles alunos. Considerando as interações discursivas promovidas nas aulas gravadas, percebemos que ambos os professores utilizam nas aulas a abordagem interativa de autoridade e o padrão predominante da interação é I-R-A - o professor faz a pergunta (I-iniciação do professor), os alunos respondem (R-resposta do aluno) e o professor avalia (A-avaliação do professor). Tanto na aula de P1 como na aula de P2 essa tríade de interação é repetida.

Percebe-se em P1 algumas pequenas mudanças em aspectos pontuais, como no reconhecimento da necessidade de um melhor planejamento, na intenção de uma prática alternativa, ou na maior atenção e consideração dadas às intervenções dos estudantes. Por outro lado, há aspectos que estão desconectados de suas intenções construtivistas, como sua concepção de avaliação sancionadora e disciplinadora. O desenvolvimento do PCK para esse professor nesse contexto de estudo mostra-se estar em evolução nos distintos componentes, cada componente mostrando uma evolução distinta dos demais e alguns componentes permanecem estagnados.

Um componente importante do modelo hexagonal parece ter uma fun- 
ção relevante no desenvolvimento do PCK - a eficácia do professor, que pôde ser observada no caso dos dois professores investigados.

P1 revela desejo de ter uma aula centrada no aluno. Embora isso apareça em seu discurso por várias vezes, na prática suas ações demonstram uma concepção de ensino-aprendizagem oposta. A tentativa de P1 de modificar suas estratégias em sala de aula acabou acarretando problemas com a gestão da aula. Assim, P1 fica no meio do caminho entre o que revela no discurso e o que consegue colocar em prática, e isso faz com que sua aula não seja coerente e o resultado com os alunos não é adequado. Considera-se que sua eficácia como professor não é boa, e ele externaliza várias vezes e de diferentes formas a sua frustração tanto sobre sua eficácia como professor quanto de sua aula. Isso deixa esse professor mais inseguro e mais propenso a mudanças que foram reveladas em suas falas, ou seja, o fator pouca eficácia de alguma forma mobiliza esse professor que se mostra em processo de busca de uma coerência para suas ações em sala de aula, embora revele estar longe ainda de obter tal empenho.

A professora P2, por sua vez, mostra-se bastante segura no que faz e ninguém coloca dúvidas sobre sua eficácia na sala de aula, nem o grupo colaborativo, nem a professora formadora nem ela mesma. Suas ações em sala de aula mostram-se coerentes com o que acredita e com o contexto em que atua. Ela faz o que a instituição e os alunos esperam dela. Utiliza um material condizente, e suas estratégias também são coerentes com seus objetivos, seus alunos e a escola. Assim, embora atue de uma forma extremamente tradicional, seguindo um roteiro estabelecido pela instituição, é muito eficaz em seu propósito. Ela percebe sua eficácia e, apesar de, em algumas falas, revelar que gostaria de mudar sua postura em sala de aula, percebe-se que não investe muito na mudança e sua eficácia reforça sua permanência no modelo didático que utiliza. Ela também não mostra frustração com a orientação utilizada e traça um paralelo com a sua história de vida. P2 atua na mesma instituição onde estudou e revela ter orgulho do que a instituição fez por ela e que gostaria de fazer o mesmo pelos seus alunos. Revela-se, assim, o papel do Contexto e da Eficácia que moldam o PCK de P2.

A eficácia parece, assim, ser um importante aspecto de desenvolvimento do PCK parecendo atuar como uma força propulsora das mudanças ou das permanências, assim como foi observado nos resultados de Park e Oliver (2008). P1 tem pouca eficácia e está em busca de mudanças, enquanto P2 se sente eficaz e assim permanece reproduzindo seu modelo de ensino de sucesso.

Por outro lado, reafirma-se a importância do contexto como forma de promoção do desenvolvimento do PCK. Na literatura já foi relatada a influência do contexto no PCK de professores (SILVA, 2012; SILVA, FERNANDEZ, 2014). Um "bom" professor com um PCK desenvolvido faz adaptações em seu ensino de acordo com a instituição em que trabalha. Nesse sentido, P2 permanece com um ensino mais tradicional, embora revele não concordar com esse modelo. Mas insiste nele, pois, além de eficaz, no contexto da instituição que P2 trabalha, é esse o modelo esperado. Assim, P2 tem eficácia e não investe muito na mudança, sua eficácia reforça sua permanência no modelo didático que utiliza. 
Concluindo, essa investigação reafirma a importância da reflexão na formação contínua de professores de forma colaborativa. O processo reflexivo apresentado permitiu que os professores se constituíssem de forma distinta e começassem a buscar novos caminhos em suas ações pedagógicas ou que se percebessem bem da forma que se encontram. Acredita-se que o importante é o professor atuar conscientemente, propor ações em sala de aula com intenções explícitas e coerentes aos seus alunos e ao seu contexto e, assim, se desenvolver profissionalmente. Os resultados sustentam que a explicitação do PCK de professores durante o processo formativo auxilia em muito esse desenvolvimento profissional.

\section{AGRADECIMENTOS}

As autoras agradecem o apoio financeiro para o grupo de pesquisa conduzido por agências governamentais brasileiras CNPq, CAPES e Fapesp (Cepid Redoxoma - Processo N. 13/07937-8).

\section{REFERÊNCIAS}

ABELL, S. K. "Research on Science Teacher Knowledge.” In: ABELL, S.K.; LEDERMAN, N.G. Handbook of research on science education, Routledge: New York, p.1105-1149, 2007. ABELL, S. K. Twenty Years Later: Does Pedagogical Content Knowledge Remain a Useful Idea? International Journal of Science Education, v.30, n.10, p.1405-1416, 2008.

BOAVIDA, A. M., \& PONTE, J. P. Investigação colaborativa: Potencialidades e problemas. In: GTI (Org.). Reflectir e investigar sobre a prática profissional. Lisboa: APM, p. 43-55, 2002.

BONARDO, J. C.; FERNANDEZ, C. Contribuições do processo de reflexão crítica para o desenvolvimento do Conhecimento Pedagógico do Conteúdo de uma professora de Química. In: LOPES, Amélia; CAVALCANTE, Maria A.S.; OLIVEIRA, Dalila A.; HIPÓLITO, Álvaro M. (Org.). Trabalho Docente e Formação: Políticas, Práticas e Investigação: Pontes para a mudança. 1ed.Porto: CIIE, v.1, p.5328-5353, 2014.

BRASIL. Ministério da Educação. Secretaria de Ensino Superior. Parecer no 9/2001, de 08 de maio de 2001. Diretrizes curriculares nacionais para a formação de professores da educação básica, em nível superior, curso de licenciatura, de graduação plena. 2001. Conselho Nacional de Educação. Conselho Pleno. Disponível em: < http://portal.mec.gov.br/cne/arquivos/ pdf/009.pdf >. Acesso em: 21 mar. 2014.

CARVALHO, A. M. P.; GIL-PÉREZ, D. Formação de professores de Ciências: tendências e inovações. São Paulo: Cortez, 8a Ed., 2003.

CARVALHO, A.M.P. A Formação de Professores: O Discurso Crítico Liberal em Oposição ao Agir Dogmático Repressivo, Ciência e Cultura, SBPC, São Paulo, v.41, n.5, p.432-434, 1989.

DEMO, P. Educar pela pesquisa. São Paulo: Autores Associados, 1996.

DEWEY, J. Como Pensamos. São Paulo: Companhia Editora Nacional, 1959.

FERNANDEZ, C. PCK - Conhecimento Pedagógico do Conteúdo: perspectivas e possibilidades para a formação de professores. In: VIII Encontro Nacional de Pesquisa em Educação em Ciências - ENPEC, Campinas, SP. Atas do VIII ENPEC - I CIEC 2011. Rio de Janeiro, RJ: ABRAPEC, v. 1. p. 1-12, 2011. Disponível em: <http://www.nutes.ufrj.br/abrapec/ viiienpec/resumos/R0370-1.pdf>. Acesso em: 3 maio 2014.

FERNANDEZ, C. Knowledge base for teaching and Pedagogical Content Knowledge (PCK): 
some useful models and implications for teachers training. Problems of Education in the Twenty First Century, v.60, p.79-100, 2014a.

FERNANDEZ, C.A base de conhecimentos para o ensino e o Conhecimento Pedagógico do Conteúdo (PCK) de professores de Química. 329 p. Tese de Livre Docência, Universidade de São Paulo, 2014b.

FERNANDEZ, C.; GOES, L. F. Conhecimento pedagógico do conteúdo: estado da arte no ensino de ciências e matemática. In: Garritz, A.; Rosales, S.F.D; Lorenzo, M.G. (Org.). Conocimiento Didáctico del Contenido. Una perspectiva Iberoamericana. 1ed.Saarbrücken, Alemania: Editorial Académica Española, p. 65-99, 2014.

FERNANDEZ, C.; LOPES, J. G. S.; BONARDO, J. C. In-service chemistry teachers reflection: a metacognitive experience. In: Berndt Ralle; Ingo Eilks. (Org.). Promoting Successful Science Education - The worth of Science Education. 1ed.Aachen: Shaker Verlag, v.1, p.145-154, 2008.

FREIBERGER, R.M., BERBEL, N.A.N. A importância da pesquisa como princípio educativo na atuação pedagógica de professores de educação infantil e ensino fundamental. Cadernos de Educação, FaE/PPGE/UFPel, Pelotas, v.37, p.207-245, 2010.

GALIAZZI, M.C., MORAES, R. Educação pela pesquisa como modo, tempo e espaço de qualificação da formação de professores de ciências, Ciência \& Educação,

v.8, n.2, p.237-252, 2002.

GARRITZ, A. PCK for dummies. Educación Química, v. 24, n. 2, p. 462-465, 2013.

GATTI, B.A., BARRETO, E.S.S., ANDRÉ, M.E.D.A. Políticas docentes no Brasil: um estado da arte. Brasília: UNESCO, 300 p., 2011.

GIROTTO JR, G. De licenciando a professor de Química: um olhar sobre o desenvolvimento do Conhecimento Pedagógico do Conteúdo. 160f. Dissertação (Mestrado em Ensino de Ciências), Universidade de São Paulo, São Paulo, 2011. Disponível em: <http://www.teses.usp.br/teses/disponiveis/81/81132/tde-31052012-100716/pt-br.php>. Acesso em: 3 mar. 2014.

GIROTTO JR, G.; FERNANDEZ, C. Following early career chemistry teachers: the development of Pedagogical Content Knowledge from pre-service to a professional teacher. Problems of Education in the Twenty First Century, v. 55 ,

p.57-73, 2013.

GOES, L. F. Conhecimento Pedagógico do Conteúdo: Estado da Arte no Campo da Educação e no Ensino de Química. 2014. 155f. Dissertação (Mestrado) apresentada ao Instituto de Física, ao Instituto de Química, ao Instituto de Biociências e à Faculdade de Educação, Universidade de São Paulo, São Paulo.

JENKINS, J. M.; VEAL, M. L. Preservice teachers' PCK development during peer coaching.Journal of Teaching in Physical Education, v. 22, n. 1, p. 49-68, 2002.

KIND, V. Pedagogical content knowledge in science education: perspectives and potential for progress. Studies in Science Education, v.2, n.45, p.169-204, 2009.

MALDANER, O.A. A formação inicial e continuada de professores de química: professores/pesquisadores. Ijuí: Ed. UNIJUI (Coleção Educação em Química), 2006.

MAMLOK-NAAMAN, R.; RAUCH, F.; MARKIC, S.; FERNANDEZ, C.How to keep myself being a professional chemistry teacher. In: Ingo Eilks; Avi Hofstein. (Org.).Teaching Chemistry A Studybook: A Practical Guide and Textbook for Student Teachers, Teacher Trainees and Teachers. 1ed.Rotterdam, The Netherlands: Sense Publishers, v.1, p.269-297, 2013.

MONTENEGRO,V.L.S. Processo reflexivo e o desenvolvimento do Conhecimento Pedagógico do Conteúdo: análise a partir de uma intervenção na formação contínua de professores de química. 270f. Dissertação (Mestrado em Ensino de Ciências), Universidade de São Paulo, São Paulo, 2011. Disponível em: <http://www.teses.usp.br/teses/disponiveis/81/81132/tde-14062012-115507/pt-br.php>. Acesso em: 3 maio 2014.

MORTIMER, E. F.; SCOTT, P. Atividade discursiva nas salas de aula de ciências: uma ferramenta sócio-cultural para analisar e planejar o ensino. Investigações em Ensino de Ciências, v.7, n.3, p.1-24, 2002.

LIMA, A. A.; NUÑEZ, I. B. A análise do Conhecimento Pedagógico do Conteúdo no Planejamento de Atividades com a utilização de Modelos no Ensino de Química. Química Nova na Escola, v. 36, p. 123-131, 2013. 
OLIVEIRA-JUNIOR, M.M. Flashes das disciplinas de formação inicial no repertório profissional de licenciandos em química. 2011. 191f. Dissertação (Mestrado) apresentada ao Instituto de Física, ao Instituto de Química, ao Instituto de Biociências e à Faculdade de Educação da Universidade de São Paulo, São Paulo, 2011. Disponível em: < http://www.teses.usp.br/teses/disponiveis/81/81132/tde-30052012-145050/pt-br.php>. Acesso em: 27 mar. 2014.

OLSON, M. Collaboration: An epistemological shift. In: H. Christiansen, L. Goulet, C. Krentz, \& M. Macers (Orgs.). Recreating relationships: Collaboration and educational reform (p. 13-25). New York, NY: State University of New York Press, 1997.

PARK, S. H.; OLIVER, J. S.Revisiting the conceptualization of Pedagogical Content Knowledge: PCK as a Conceptual Tool to Understand Teachers as Professionals. Research in Science Education, v. 38, n. 3, p. 261-284, 2008.

PEREIRA, P. G. E. M.; FERNANDEZ, C. Indícios do modelo integrativo no desenvolvimento do PCK em licenciandos em química durante o estágio supervisionado. Revista de Educación de las Ciencias, v. 14, p. 74-78. 2013.

PERRENOUD, P. Formar professores em contextos sociais em mudança: prática reflexiva e participação crítica. Revista Brasileira de Educação, n.12, p.5-21, 1999.

PIMENTA, S. G. Professor reflexivo: construindo uma crítica. In: PIMENTA, S. G.; GHEDIN (orgs). Professor reflexivo no Brasil: gênese e crítica de um conceito. 4. ed. São Paulo: Cortez, 2006.

PIROLA, S. M. F.; FERREIRA, M. C. C. O problema da 'indisciplina dos alunos': Um olhar para as práticas pedagógicas cotidianas na perspectiva de formação continuada de professores. Olhar de professor, Ponta Grossa, 2007. 10(2), 81-99. Disponível em:<http://www.uepg.br/olhardeprofessor>. Acesso em: 15 mar. 2009.

PONTE, J. P. O Estudo de Caso na Investigação em Educação Matemática, Quadrante, v.3, n.1, p.318. 1994. Disponível em:<http://www.educ.fc.ul.pt/do

centes/jponte/docs-pt/94-Quadrante(Estudo\%20caso).doc>. Acesso em: 15 mar. 2009.

PONTE, J.P. Didáticas específicas e construção do conhecimento profissional. In: CONGRESSO

DE SPCE, 4, 1998. Aveiro. Conferência no IV Congresso de SPCE - Aveiro/PT, Disponível em: http://www.educ.fc.ul.pt/docentes/jponte/d

ocs-pt\%5C99-Ponte(Aveiro).pdf>. Acesso em: 15 mar. 2009.

PONTE, J. P. Tecnologias de informação e comunicação na formação de professores: Que desafios para a comunidade educativa? Revista Ibero-Americana de Educação, n. ${ }^{\circ}$ 24, Setembro - Dezembro 2000) e na Revista 6 (Dezembro 2002), Departamento de Educação Básica, Ministério da Educação, 2000.

PONTE, J. P. Estudiando el conocimiento y el desarrollo profesional del profesorado de matemáticas, Teoría, crítica y práctica de la educación matemática, p.83-98, 2012

PONTE, J.P. Theoretical frameworks in researching mathematics teacher knowledge, practice, and development, Journal of Mathematics Teacher Education, p. 319-322, 2013

PONTE, J. P., \& Chapman, O. (2008). Preservice mathematics teachers' knowledge and development. In: L. English (Ed.), Handbook of international research in mathematics education (2nd ed., pp. 225-263). New York, NY: Routledge.

REALI, A. M. M. R.; TANCREDI, R. M. S. P.; MIZUKAMI, M. G. N. Desenvolvimento profissional de professores iniciantes em programa de Mentoria online: experiências de ensino e aprendizagem (EEA) como ferramentas investigativas e formativas. Revista e-Curriculum (PUCSP), v. 12, p. 1033-1056, 2014.

SALAZAR, S. F. El conocimiento pedagógico del contenido como categoría de estudio de la formación docente. Actualidades investigativas em educación, v. 5, n. 2, 2005. Disponível em: < http://revista.inie. ucr.ac.cr/uploads/tx_magazine/

conocimiento.pdf>. Acesso em: 25 jul. 2014.

SALES, M. G. P. Investigando o conhecimento pedagógico do conteúdo sobre “soluções” de uma professora de Química. 253f. Dissertação (Mestrado em Ensino de Ciências), Universidade de São Paulo, São Paulo, 2010. Disponível em: <http://www.teses.usp.br/teses/disponiveis/81/81132/tde-21022011155615/pt-br.php>. Acesso em: 3 jun. 2014. 
SANTOS, V.L.; FERNANDEZ, C. Processo reflexivo: análise a partir de uma intervenção na formação contínua de professores de Química. In: VII ENPEC Encontro Nacional de Pesquisa em Educação em Ciências, 2009, Florianópolis. Anais do Encontro Nacional de Pesquisadores em Educação em Ciências, v. 1. p. 1-12.

SCHÖN, D. A. The reflective practitioner. New York: Basic Books, 1983.

SCHÖN, D. Formar professores como profissionais reflexivos. In: Os professores e sua formação. (Org). De Nóvoa; Lisboa, Portugal, Dom Quixote, p.79-91, 1992.

SHULMAN, L. Knowledge and teaching: Foundations of the new reform. Harvard Educational Review, v. 57, n. 1, p. 1-22, 1987.

SHULMAN, L. S. Those who understand: knowledge growth in teaching. Educational Researcher, v. 15 , n. 4 , p. $4-14,1986$.

SILVA, A. N. Um professor de Química e dois contextos escolares: o conhecimento pedagógico do conteúdo em ação. 2012. 154f. Dissertação (Mestrado em Ensino de Ciências), Universidade de São Paulo, São Paulo, 2012. Disponível em: <http://www.teses.usp.br/teses/disponiveis/81/81132/tde-25022013-132509/pt-br.php>. Acesso em: 3 jun. 2014.

SILVA, A.N.; FERNANDEZ, C. A chemistry teacher and two scholar contexts: the pedagogical content knowledge in action. In: 2nd International Congress of Science Education, 2014, Foz de Iguaçu. Paraná.Proceedings of the 2nd International Congress of Science Education. Foz de Iguaçu: UNILA, v. 15. p. 62-62.

SMYTH, J. Reflection in Action. Victória: Deakin University Press, 1986.

SMYTH, J. Una pedagogía crítica de la práctica en el aula. Revista de Educación, v. 294, p. 275-300, 1991.

TACOSHI, M.M.A. Avaliação da Aprendizagem em Química: concepções de ensino-aprendizagem que fundamentam esta prática.2008. 217f. Dissertação (Mestrado em Ensino de Ciências), Universidade de São Paulo, São Paulo, 2008. Disponível em: http://portal.if.usp.br/cpgi/sites/default/ files/Marina_Miyuki_Akutagawa_

Tacoshi.pdf $>$. Acesso em: 3 out. 2014.

VAN DRIEL, J. H., VERLOOP, N.; DE VOS, W. Developing science teachers' pedagogical content knowledge. Journal of Research in ScienceTeaching, 35(6), 673-695, 1998.

Data de recebimento: $25 / 07 / 2014$

Data de aprovação: 14/01/2015

Data da versão final: $10 \mathrm{a} / 02 / 2015$

\section{Contato:}

Carmen Fernandez

Universidade de São Paulo, Instituto de Química, Departamento de Química Fundamental.

Av. Prof. Lineu Prestes, 748 - Bloco 07 Superior - sala 773

Cidade Universitária - Sao Paulo, SP - Brasil - 05508-900

Email: carmen@iq.usp.br 